\title{
Impact of a weekly dance class on the functional mobility and on the quality of life of individuals with Parkinson's disease
}

\section{Lisa Heiberger ${ }^{1}$, Christoph Maurer ${ }^{1}$, Florian Amtage ${ }^{1}$, Ignacio Mendez-Balbuena ${ }^{1}$, Jürgen Schulte-Mönting ${ }^{2}$, Marie-Claude Hepp-Reymond ${ }^{3}$ and Rumyana Kristeva ${ }^{1}{ }^{*}$}

${ }^{1}$ Cortical Motor Control Laboratory, Department of Neurology and Neurophysiology, University Hospital of Freiburg, Freiburg im Breisgau, Germany

2 Institute for Medical Biometry and Medical Informatics, Freiburg im Breisgau, Germany

${ }^{3}$ Institute of Neuroinformatics, Eidgenössische Technische Hochschule Zürich, University of Zürich, Zurich, Switzerland

\section{Edited by:}

Hari S. Sharma, Uppsala University, Sweden

\section{Reviewed by:}

Bogdan O. Popescu, University Hospital Bucharest, Romania

Richard Camicioli, McGill University, Canada

\section{*Correspondence:}

Rumyana Kristeva, Cortical Motor Control Laboratory, Department of Neurology and Neurophysiology, University Hospital of Freiburg, Breisacherstr. 64, 79106 Freiburg im Breisgau, Germany. e-mail: rumyana.kristeva@uniklinikfreiburg.de
Individuals with Parkinson's disease (PD) mainly suffer from motor impairments which increase the risk of falls and lead to a decline of quality of life. Several studies investigated the long-term effect of dance for people with PD. The aims of the present study were to investigate (i) the short-term effects of dance (i.e., the effect immediately after the dance class) on motor control in individuals with PD and (ii) the long-term effects of 8 months of participation in the weekly dance class on the quality of life of the PD patients and their caregivers. The dance lessons took place in a ballet studio and were led by a professional dancer. Eleven people with moderate to severe PD (58-85 years old) were subjected to a motor and quality of life assessments. With respect to the motor assessments the unified Parkinson disease rating scale III (UPDRS III), the timed up and go test (TUG), and the Semitandem test (SeTa) before and after the dance class were used. With respect to the quality of life and well-being we applied quality of life scale (OOLS) as well as the Westheimer questionnaire. Additionally, we asked the caregivers to fill out the Questionnaire for caregivers. We found a significant beneficial short-term effect for the total score of the UPDRS motor score. The strongest improvements were in rigidity scores followed by significant improvements in hand movements, finger taps, and facial expression. No significant changes were found for TUG and for SeTa. The results of the questionnaires showed positive effects of the dance class on social life, health, body-feeling and mobility, and on everyday life competences of the PD patients. Beneficial effect was also found for the caregivers. The findings demonstrate that dance has beneficial effect on the functional mobility of individuals with PD. Further, dance improves the quality of life of the patients and their caregivers. Dance may lead to better therapeutic strategies as it is engaging and enjoyable.

Keywords: dance, Parkinson disease, intervention, motor scores, rigidity, quality of life

\section{INTRODUCTION}

Parkinson's disease (PD) is a neurodegenerative movement disorder of the central nervous system which especially impairs patients' motor skills, as well as the autonomic nervous functions and state of mind. PD is characterized by muscle rigidity, tremor, postural instability, gait abnormalities, a slowing (bradykinesia), and a loss of physical movement (akinesia). People with PD often report that interactions with the local environment are also severely affected (Harris, 2008). In general, individuals with PD experience a decline of their functional mobility that increases the risk of falls. Individuals with PD may also show changes in their mental status, including significant depression and disturbance of memory and cognition. As a consequence of the insufficient physical activity, the disease is associated with osteoporosis, muscle weakness, and low self esteem, which leads to a withdrawal from activities, social isolation, and a decline of the quality of life (Bloem et al., 2004).
Treatment options in PD are manifold. The pharmacological (medications, L-DOPA) and surgical treatments [deep brain stimulation (DBS)] target mainly motor symptoms, but are in the late state of the disease - not sufficient to recover motor symptoms completely. Additional therapeutic interventions are required to further improve motor symptoms. In particular, balance and gait difficulties and the impaired functional mobility are treated by supplementary physio- and movement therapy with traditional exercise approaches, to further reduce the risk of falling, enhance mobility, and practise the adjustments to environmental demands.

Numerous studies have demonstrated that physical activity for individuals with PD has positive effects on gait velocity, muscular strength, balance, and quality of life (Goodwin et al., 2008). According to these findings, various exercise programs have been developed for patients with PD, such as balance practice, aerobic training, treadmill training, water gymnastics, and 
stretching-power-exercises. Unfortunately, the compliance and regular participation, which is essential for the efficacy of the exercise programs, is often insufficient. Therefore, more attractive and enjoyable activities, like dance, have to be offered to assure the regular participation of the patients.

Dance comprises a large variety of features shown to have beneficial effects in PD, including improvements in rhythmic motor coordination and balance. Dance also offers auditory, visual and sensory stimulation, musical experience, musicality, social interaction, memory, motor learning, emotional perception and expression, emotional interaction (Kattenstroth et al., 2010). Dance has an important impact on health; it influences the mood (Jeong et al., 2005), everyday competences (Kattenstroth et al., 2010) and social life (Palo-Bengtsson et al., 1998). Further, the music contributes a lot to the positive effects of dance. Music perception provokes vitalization that influences the immune system (Koelsch and Siebel, 2005). All these features make dance an "enriched environment" which stimulates the brain plasticity through neurotrophines (Kattenstroth et al., 2010). Dance has the particular advantage that it is enjoyable and engaging, which promotes the motivation for a regular participation in dance classes, a high compliance and little drop-outs (Fallik, 2007; Westheimer, 2008; Earhart, 2009; Hackney and Earhart, 2009a,b). Most studies employing dancing as an intervention in elderly revealed longterm effects, such as improvements in balance, walking, everyday competences, and physical fitness (McKinley et al., 2008; Eyigor et al., 2009; Hui et al., 2009; Kattenstroth, 2009; Wallmann et al., 2009). The beneficial effect of dance was also shown for complex gait tasks (Jacobson, 2005). Furthermore, Kattenstroth et al. (2010) have shown that multi-year dancing promotes a wide-range of beneficial effects for elderly healthy people, which cover motor, perceptual, and cognitive abilities. Berrol (1997) examined the benefits of dance therapy for individuals with various neurological deficits and described improvements in balance, gait, and cognitive performance.

So far, only few studies have examined the benefits of dance for people with PD. Two studies explored the long-term effect of dance intervention on the mobility of PD patients: Westbrook and McKibben (1989) noticed in their comparative study between a Parkinson dancing group and a Parkinson exercise group improved movement initiation in the dancing group. Patients with PD who participated in progressive Argentine tango or American smooth waltz and foxtrot lessons for 13 weeks improved on standard clinical measures of locomotion, balance, and motor control (Hackney and Earhart, 2009a).

To our knowledge, there is no study investigating the effect of the dance on the mobility immediately after the dance class. The aim of this study was to investigate the immediate effect after the dance class (called short-term effect) on motor control in individuals with PD and in particular how various aspects of the mobility are changed by the dance class. For this purpose, the patients were subjected to motor tests immediately before and after the dance class in the ballet studio. The investigation was performed only once after 8 months regular participation in the weekly dance class.

A second arm of the study was to investigate the quality of life of the patients and their caregivers after regular participation in the dance class. The findings of Westheimer (2008) about increased quality of life after 17 months participation at the PD dance class lead us to the prediction, that our dance class will also enhance the quality of life and the well-being of the participants. The patients and their caregivers were subjected to this investigation also after 8 months regular participation in the dance class.

\section{MATERIALS AND METHODS PATIENTS AND THEIR CAREGIVERS}

Eleven people with moderate to severe PD who participated regularly for 8 months (25 dance class lessons) in a weekly dance class were investigated. The patients were $58-85$ years old $(71.3 \pm 8.4$ years; six women, five men). PD was diagnosed by their neurologist according to the ICD-10 criteria. The PD was on average detected 8 years (range: $2-16$ years) before the study. Following the stages of the disease according to the classification of Hoehn and Yahr the patients were assigned to the stages II-IV. Three of the patients were treated by bilateral DBS in the subthalamic nucleus.

In addition to these 11 patients, three new PD patients called here de novo (two male, one female; 66-71 years old; PD grade III-IV) were investigated after only one dance class (Table 1).

Four caregivers (age 67-79; two women and two men) partners or spouses of the patients and who had also taken part for 8 months in the weekly dance class were interviewed.

All participants provided written informed consent prior to participation. The study was approved by the local ethical committee.

\section{PARADIGM}

The design of the PD dance class was a modified version of the weekly dance class offered by Mark Morris Dance Group (MMDG)/Brooklyn Parkinson Group in New York since 2001 (Westheimer, 2008) for patients with PD and their caregivers. We introduced a newly elaborated Parkinson dance class which took

Table 1 | Demographic data and stage of disease of the PD patients.

\begin{tabular}{|c|c|c|c|c|c|c|c|c|c|c|c|c|c|c|}
\hline Patients & P1 & $\mathbf{P 2}$ & P3 & P4 & P5 & P6 & P7 & P8 & P9 & P10 & P11 & $\mathbf{P} * 1$ & $\mathbf{P} * 2$ & $\mathbf{P} * 3$ \\
\hline Sex & $\mathrm{m}$ & $f$ & $\mathrm{~m}$ & $\mathrm{~m}$ & $f$ & f & $f$ & $f$ & $\mathrm{~m}$ & $f$ & $\mathrm{~m}$ & $\mathrm{~m}$ & $f$ & $\mathrm{~m}$ \\
\hline Age & 73 & 85 & 75 & 80 & 65 & 72 & 65 & 81 & 64 & 58 & 66 & 71 & 67 & 66 \\
\hline PD grade (Hoehn and Yahr) & IV & III & III & IV & II & III & $\|$ & III & IV & IV & III & IV & III & III \\
\hline
\end{tabular}

$P D$, Parkinson disease; $P 1-P 11$, patient $1-11 ; P^{*} 1-3$, de novo patient $1-3 ; m$, male; $f$ female. 
place once a week $(1.15 \mathrm{~h})$ in Freiburg, Germany. The classes were led by a professional dance teacher in the welcome environment of a ballet studio.

\section{The concept of the dance class for PD and their caregivers in Freiburg, Germany}

Dance elements. The movement sequences of the PD dance class combined elements of ballet, jazz steps, contemporary dance, dance theater, and choreographic elements.

Classical ballet sequences were chosen because they include versatile aspects that lead to a better body-feeling and -awareness. Ballet sequences are structured which facilitate movement execution. Ballet improves posture, flexibility, and muscle strength accompanied by grace and elegance which stimulate esthetic perception. Balance can be ameliorated by increased internal body tension. Coordination and proprioceptive acuity (Ramsay and Riddoch, 2001; Schweiger, 2009) are also improved by classical.

Jazz sequences are performed to a regularly and predictable beat which help to perform rhythmic walking steps. Rhythm is one of the most important and helpful elements of dance (Brown et al., 2006) and can best be expressed through jazz music.

The Contemporary dance incorporates very different forms of movement and consists in a synthesis of various dance techniques - such as modern dance, release technique, improvisation. With awareness of own breath and easy flow of energy dancing becomes conscious and more natural.

During dance theater sequences, the body movements are not the only means of expression. Dance theater uses also facial expression (pantomime), speech, and self-produced noises. All kinds of dance and movements, such as everyday gestures, can be used. Mostly, stories are told about people's activities and society. The individual is in constant exchange with others and humor often plays an important role.

In our dance class we took choreographic elements from famous choreographers.

\section{Structure of the dance lesson}

The dance lesson was based on an adapted three-part-format of a traditional ballet class:

I. The warming-up consists of physical and mental dance exercises to produce an optimal psycho-physical constitution for dancing and is practised with one hand touching at the barre for proprioceptive feedback. As in the dance class in New York, we added a warming-up part with participants seating in a circle, so that a premature fatigue was prevented. The exercises at the ballet barre reinforced the balance and were a good transition from the sitting exercises to dancing in the center of the room.

II. Dance exercises in the center of the room were executed without tactile feedback. Choreographed sequences were performed across the floor with the teacher leading.

III. The bowing, "la révérence": As in a traditional ballet class the PD dance class ended with a bowing, which was integrated to the farewell in a standing circle holding hands.

\section{Elements of the dance class in their sequential order}

Table 2 lists the successive elements of the dance class, their usefulness, and the music to them. Two elements ("name game" and "farewell") were the same as in the dance class in New York described by Westheimer (2008). A video of our dance class can be seen under http://www.uniklinik-freiburg.de/neurologie/live/ forschung/xpeeg.html.

\section{TESTS}

Motor tests

Unified Parkinson disease rating scale III (motor exam). For this study, we used part III of the unified Parkinson disease rating scale III (UPDRS), the motor examination. It consists of 14 items: speech, facial expression, tremor at rest, postural and action tremor, rigidity, finger tapping, hand movements, hand pronation/supination, leg agility, standing-up from chair, posture, gait, postural stability, body bradykinesia, and hypokinesia (Fahn et al., 1987).

Timed up and go (Podsiadlo and Richardson, 1991). The test measures speed during several functional maneuvers. On request, the subject has to walk normally to a line drawn at $3 \mathrm{~m}$ distance, turn around, and go back to the chair and sit down in the starting position.

Good test-retest reliability (ICC $=0.97-0.99$ and Spearmans correlation coefficient $=0.93$ ) have been demonstrated in many studies (Podsiadlo and Richardson, 1991; Ng and Hui-Chan, 2005).

Semitandem test. The test is used in clinical practice and evaluates the balance and postural stability. The subject should stand for $15 \mathrm{~s}$ with one foot behind the other so that the big toe of one foot is touching the side of the heel of the other. The balance test is performed with open eyes.

\section{Questionnaires of quality of life and well-being of the patients}

To asses the subjective effect of dance we used three questionnaires. Two of them were also used in Westheimer (2008), but we added some slight modifications in them. The third one is questionnaire for the caregivers, which was created by us.

Questionnaire of the quality of life. This questionnaire was used to evaluate the impact of dance on the quality of life of the patients after taking part in the weekly dance class for 8 months. This was evaluated using the quality of life scale (QOLS) from the Oregon Health and Sciences University (Quality of Life Scale in Appendix). This questionnaire including 16 items is validated for persons with chronic diseases. We have used a modified version of the test described in Westheimer (2008) where Brooklyn Parkinson Group added a 17th item (moving around - walking, standing-up).

On a scale from 1 to 7 ( $1=$ terrible, $2=$ unhappy, $3=$ mostly dissatisfied, $4=$ mixed, $5=$ mostly satisfied, $6=$ pleased, $7=$ delighted), the patients had to answer how satisfied they are in different domains of their life: health, relationships, material wellbeing, personal, social, and community activity. An additional question explores if there were improvements in one or more items since the participation of the dance class. This last question 
Table 2 | Dance elements in their sequential order.

\begin{tabular}{|c|c|c|c|}
\hline Type of exercise & Exercise & Usefulness & Music \\
\hline Welcome & "Name game" & $\begin{array}{l}\text { Individual presentation, establishing contacts, } \\
\text { improvisation, creativity, observation, memory }\end{array}$ & Royal Academy Vol. 4 Track 1 \\
\hline Warming-up/breath & "Swimming and flying" & Body awareness, breathing, posture, proprioception & Royal Academy Vol. 5 Track 1 \\
\hline Suppleness & $\begin{array}{l}\text { "Joint movements," "water } \\
\text { lily" }\end{array}$ & $\begin{array}{l}\text { Exercises against rigidity for neck, shoulders, wrists, } \\
\text { hands, and ankles }\end{array}$ & $\begin{array}{l}\text { Royal Academy Vol. } 5 \text { Track 3, Dance } \\
\text { with Margot Track } 4\end{array}$ \\
\hline Foot exercises & "Tendus," "Jettés" & $\begin{array}{l}\text { Warming-up and stretching of the feet, coordination, } \\
\text { reactivity }\end{array}$ & $\begin{array}{l}\text { Royal Academy Vol. } 5 \text { Track 5, Royal } \\
\text { Academy Vol. } 5 \text { Track } 8\end{array}$ \\
\hline Ballet barre & "Ronds de jambs" & Balance, postural stability & Royal Academy Vol. 4 Track 13 \\
\hline exercises & "Balançoire" & & \\
\hline Jazz steps & "New Orleans Jazz" & Walking exercise, rhythm, coordination & $\begin{array}{l}\text { Putumayo presents: "New Orleans" } \\
\text { Track } 3\end{array}$ \\
\hline Telling stories & "Butterfly", "Spanish dance" & $\begin{array}{l}\text { Expression, esthetics and grace, imagination, motor } \\
\text { imagery }\end{array}$ & $\begin{array}{l}\text { Royal Academy Vol. } 4 \text { Track } 23 \text { (instru- } \\
\text { mental version "my way," Frank Sina- } \\
\text { tra), Soundtrack "Chocolat" Track } 18 \\
\text { "Caravan" }\end{array}$ \\
\hline $\begin{array}{l}\text { Contact } \\
\text { improvisation }\end{array}$ & "The ant" & $\begin{array}{l}\text { Stimulation of proprioception, mobility, reactivity, } \\
\text { agility }\end{array}$ & Royal Academy Vol. 4 Track 40 \\
\hline $\begin{array}{l}\text { Hand/finger } \\
\text { exercises }\end{array}$ & $\begin{array}{l}\text { "The seasons: petals, leaves, } \\
\text { snowflakes," "the piano" }\end{array}$ & $\begin{array}{l}\text { Fine motor skills, dexterity, contact, exchange, } \\
\text { interaction, use of external input }\end{array}$ & $\begin{array}{l}\text { Royal Academy Vol. } 4 \text { Track 39, Sound- } \\
\text { track Amélie Poulain Track } 4 \text { "Comptine } \\
\text { d'un autre été " }\end{array}$ \\
\hline Pair dance & $\begin{array}{l}\text { "Chocolat" } \\
\text { "Clouds" } \\
\text { "Waltz" }\end{array}$ & $\begin{array}{l}\text { Relationship, contact, balance, postural stability, } \\
\text { movement initiation, walking, synchronicity, } \\
\text { proprioceptive feedback }\end{array}$ & $\begin{array}{l}\text { Soundtrack "Chocolat" Track } 4 \text { "Viane } \\
\text { sets up shop" Dance with Margot Track } \\
\text { 29, Royal Academy Vol. 4 Track } 34\end{array}$ \\
\hline Group dance & $\begin{array}{l}\text { "Folk dance"(Breton, Greek), } \\
\text { "Louis Armstrong - Dance" }\end{array}$ & $\begin{array}{l}\text { Synchronicity, movement initiation, walking, sense } \\
\text { of community, proprioceptive feedback, balance }\end{array}$ & $\begin{array}{l}\text { Putumayo presents: "New Orleans" } \\
\text { Track } 3\end{array}$ \\
\hline $\begin{array}{l}\text { Choreography dance } \\
\text { theater }\end{array}$ & $\begin{array}{l}\text { Modified "Pina Bausch" } \\
\text { Dance (Kontakthof 13/16) } \\
\text { "Boat trip" }\end{array}$ & $\begin{array}{l}\text { Memory, cognition, coordination, synchronicity, } \\
\text { expression facial expression, imagination, motor } \\
\text { imagery, humor, laughing }\end{array}$ & $\begin{array}{l}\text { Soundtrack Amélie Poulain Track } 7 \\
\text { "Guilty" Soundtrack Amélie Poulain } \\
\text { Track } 1 \text { "J'y su is jamais allé »Track } 5 \text { "la } \\
\text { noyée " }\end{array}$ \\
\hline Farewell & "la révérence" & $\begin{array}{l}\text { Body awareness, perception, relaxing, breathing, } \\
\text { posture, relationship, sense of community }\end{array}$ & $\begin{array}{l}\text { Royal Academy Vol. } 4 \text { Track } 27 \\
\text { (Gymnopédie No. 1, Eric Satie) }\end{array}$ \\
\hline
\end{tabular}

is essential to get information about the impact of dance on the quality of life.

Modified questionnaire of Westheimer (2008) on the well-being of the patients immediately after the dance class. This questionnaire was used for the evaluation of the well-being of the patients immediately after the dance class [Modified Questionnaire of Westheimer (2008) in Appendix].

It contains five closed and two open questions. The five closed questions ask about the body-feeling, the mood, the impact of dance on everyday life and the mobility of the patients. The first three questions (A-C) have been taken over from Westheimer (2008). We added two additional questions (D, E) about the duration of the impact of dance class on the quality of life on a daily basis (D) and about the mobility after dance class (E). These two questions were added to evaluate possible relationship between the results of the questionnaire and the motor tests and because to our knowledge, no study has examined the duration of the impact of dance class before. The last two open questions (F) were also taken from Westheimer (2008) to explore the motivations of the participants to join the dance class.
The rating was on a scale of 1 ("much better") to 5 ("much worse"). The rating for question $\mathrm{D}$ was from 1 (minutes) to 4 (weeks).

Questionnaire for caregivers. This questionnaire was developed by us to take into account the judgment of the caregiver about the disease of the partner. The caregiver has followed the disease pattern of the partner since the beginning and can therefore provide a more accurate assessment of possible improvements (Questionnaire for Caregivers in Appendix). We have taken the first three questions (A1-3) from Westheimer (2008) and adapted them to the caregivers. The questions $(\mathrm{B}-\mathrm{F})$ have been worked out by us.

The questions $\mathrm{A} 1-\mathrm{A} 3$ address the mobility, mood, and influence of dance in everyday life of his/her partner. Question B explored possible changes in the relationship between caregiver and patient since the participation of the dance class. The questions $\mathrm{C} 1-\mathrm{C} 3$ should note the influence of dance class on the everyday life of the couple at home; for example the custom to listen to music or to dance together, or to repeat the dance exercises at home. The last questions (D-F) are related to the well-being of the caregiver him/herself during and after the dance class to explore possibly 
changes since the participation of the dance class. The scale of assessment is adapted to each question:

- A: from 1 ("much worse") to 5 ("much better")

- B: Yes/No question; open question: "If yes, please describe in detail."

- C1-C2: from 1 (much less than before participating at dance class) to 5 (significantly more since the participation at dance class)

- C3: from 1 (never) to 5 (always)

- D: from 1 ("much worse") to 5 ("much better")

- E-F: Yes/No question; open question: "If yes, please describe in detail."

\section{PROCEDURE OF THE INVESTIGATION}

\section{Motor evaluation of the short-term effects}

Each patient was tested in the ballet studio before and immediately after the dance class. The evaluation implied the UPDRS, the TUG, and the SeTa. The order of the examination was the same before and after the dance class. The evaluation took about $20 \mathrm{~min}$ and was videotaped.

\section{Quality of life evaluation}

To investigate the direct effect of dance on the well-being of the patients we used the modified questionnaire of Westheimer (2008), which was filled out immediately after the dance class in the ballet studio after the motor evaluation.

The Quality of life and the caregivers' questionnaire were handed out to all patients and caregivers at the same time of participation in the dance class. The patients filled out the questionnaires alone at home to preserve their privacy.

\section{DATA COLLECTION AND STATISTICAL ANALYSIS}

The videotaped motor examination was also evaluated by a blinded neurologist.

For comparison of the results from UPDRS, TUG, and SeTa tests before and after the dance class we used the Sign Test. All values presented are means and SE of the mean (SEM).

For the evaluation of the questionnaires we specified the absolute frequencies for each question and illustrated them with bar graphs.

\section{RESULTS}

\section{RESULTS OF THE MOTOR EVALUATION}

\section{Unified Parkinson disease rating scale III (motor scores)}

The results show a significant short-term effect for the total score of the UPDRS motor score (before: $23.7 \pm 3.4$; after: $15.5 \pm 3 ; p=0.001, n=11)$ and also for some specific items (Figure 1). The strongest improvements occur in rigidity scores $(p=0.002)$, followed by significant improvements in hand movements $(p=0.002)$, finger taps $(p=0.02)$, and facial expression $(p=0.01)$.

To investigate in detail whether the rigidity improvement was distal or proximal, we compared the axial vs. distal rigidity (neck vs. arms and legs). Significant effects were found only for the limbs (right $\operatorname{arm} p=0.02$, left $\operatorname{arm} p=0.03$, right leg $p=0.03$, left leg $p=0.03$ ) but not for the neck (Figure 2).
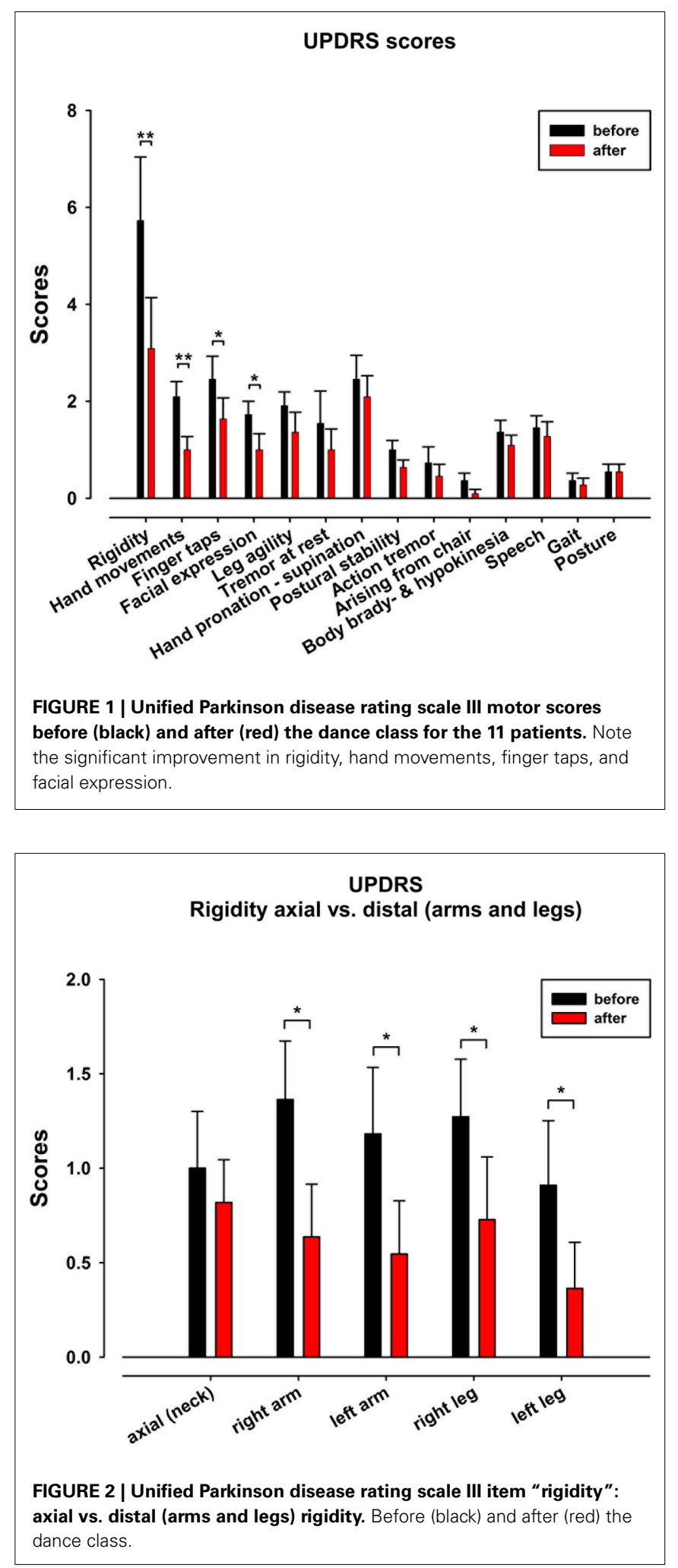

The examination of the three de novo patients revealed similar improvement of the UPDRS III scores. Again the strongest improvements were for rigidity, facial expression, finger-, hand-, and leg movements (Table 3 ). 
Results from the timed up and go test and Semitandem test

No significant changes were observed for the 11 patients neither for TUG (before: $10.6 \pm 0.5 \mathrm{~s}$; after: $9.9 \pm 0.7 \mathrm{~s}$ ) nor for SeTa (before $11.9 \pm 1.3 \mathrm{~s}$; after: $10.3 \pm 1.6 \mathrm{~s}$ ). However, the TUG showed a trend toward improvement in 9 out of the 11 patients.

\section{RESULTS OF THE OUESTIONNAIRES}

Quality of life scale

After marking how satisfied they are on the 17 items (Table 4), patients were asked to note whether they felt that any of the items had changed for the better as a result of attending the dance class and if so, which ones. Figure 3 displays the items that received the highest number of responses. The two items with most responses include "active recreation" (O) and "mobility" (Q). "Socializing" (M) received the second most responses. It is followed by the items with the third most responses: "health" (B), "relationships" (C), "helping others" (social encouragement) (G) and "expressing yourself creatively" (L).

Modified questionnaire of Westheimer (2008)

The answers to the closed questions were as follows:

A. Body-feeling after dance class (Figure 4A): 8 out of 11 patients felt improvement of their body-feeling immediately after the dance class.

Table 3 | Unified Parkinson disease rating scale III results of the three de novo patients.

\begin{tabular}{|c|c|c|c|c|c|c|c|c|c|}
\hline \multirow{2}{*}{$\begin{array}{l}\text { UPDRS } \\
\text { De novo patients }\end{array}$} & \multicolumn{3}{|c|}{ Before } & \multicolumn{3}{|c|}{ After } & \multicolumn{3}{|c|}{ Difference } \\
\hline & $P * 1$ & $P * 2$ & $P * 3$ & $P * 1$ & $P * 2$ & $P * 3$ & $P * 1$ & $P * 2$ & $P * 3$ \\
\hline Facial expression & 3 & 3 & 3 & 2 & 2 & 2 & -1 & -1 & -1 \\
\hline Tremor at rest & 1 & 0 & 4 & 0 & 0 & 4 & -1 & 0 & 0 \\
\hline Action tremor & 0 & 0 & 2 & 0 & 0 & 2 & 0 & 0 & 0 \\
\hline Finger taps & 4 & 1 & 4 & 4 & 0 & 2 & 0 & -1 & -2 \\
\hline Hand movements & 4 & 2 & 4 & 4 & 1 & 2 & 0 & -1 & -2 \\
\hline Hand pronation-supination & 4 & 4 & 3 & 4 & 2 & 2 & 0 & -2 & -1 \\
\hline Leg agility & 5 & 4 & 4 & 2 & 2 & 4 & -3 & -2 & 0 \\
\hline Arising from chair & 1 & 0 & 1 & 0 & 0 & 1 & -1 & 0 & 0 \\
\hline Posture & 2 & 1 & 2 & 1 & 0 & 2 & -1 & -1 & 0 \\
\hline Total score & 44 & 24 & 47 & 33 & 14 & 38 & -11 & -10 & -9 \\
\hline
\end{tabular}

UPDRS, unified Parkinson disease rating scale III; $P^{*} 1, P^{*} 2, P^{*} 3$, de novo patient 1, de novo patient 2, de novo patient 3.

Table 4 | Quality of life scale, response frequencies.

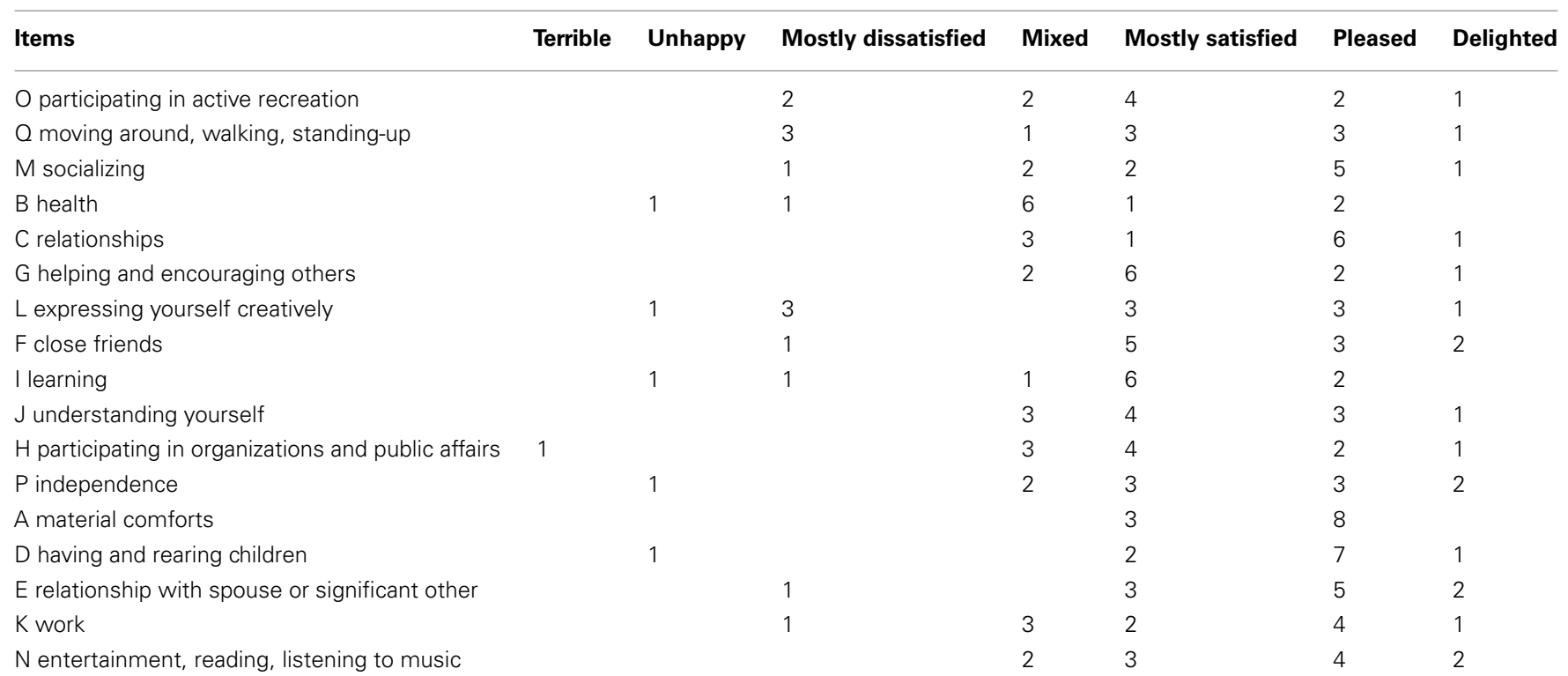




\section{Quality of life scale (QOLS)}

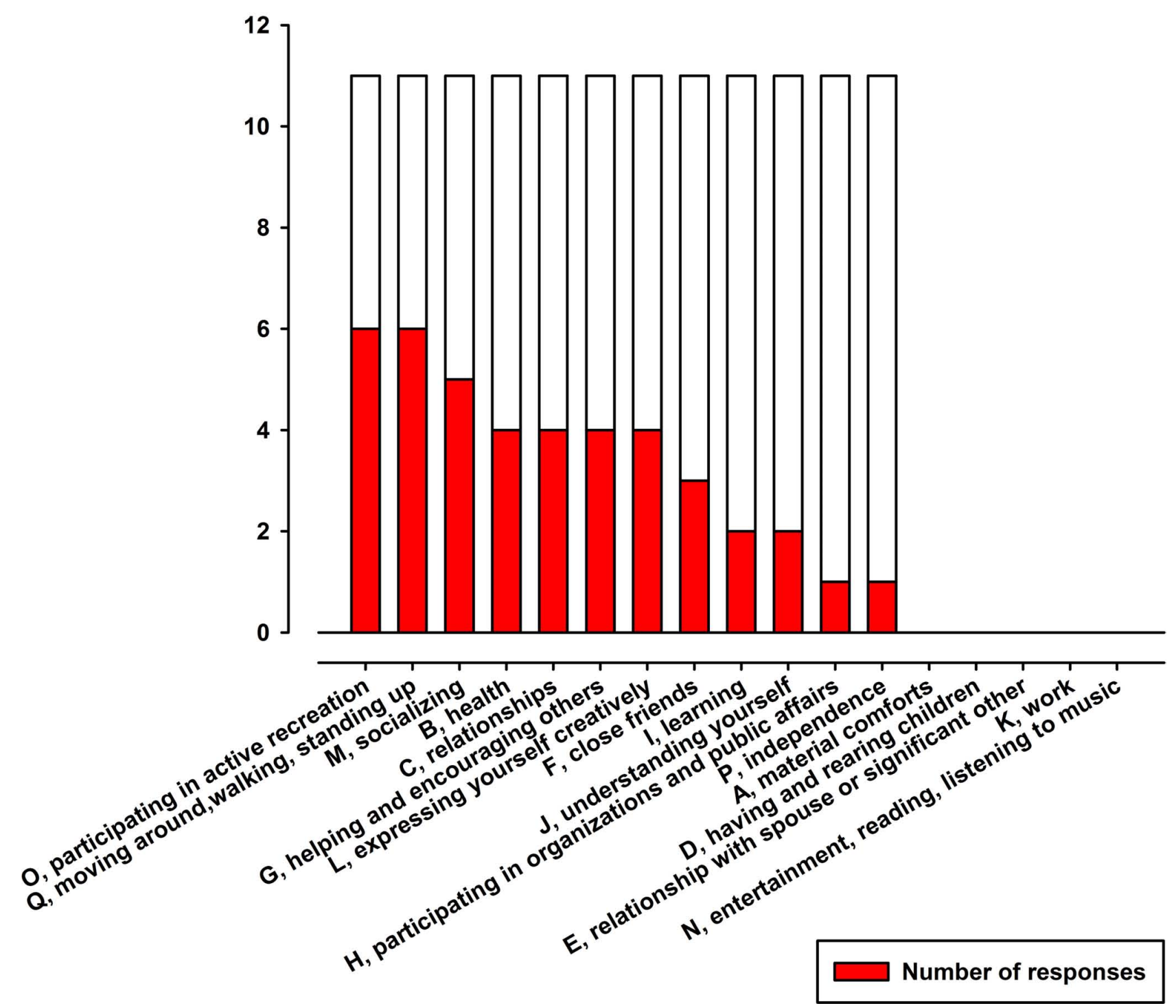

FIGURE 3 | Absolute frequencies of the items of QOLS. Note that the items are represented in order from highest number of improvement responses to lowest.

B. State of mind after dance class (Figure 4B): 9 out of 11 felt an improvement of their state of mind after the dance class.

C. Dance class impact on the quality of life in everyday life (Figure 4C): 7 out of 11 patients feel the consequences of the dance class impact their quality of life on a daily basis.

D. Duration of the impact on the quality of life (Figure 4D): from the seven patients who felt an impact, three patients felt the effect of the dance class for a few hours; four patients told that the effect of the dance class lasted for several days but not up to the next dance class.
E. Mobility after the dance class (Figure 4E): 10 from 11 patients felt an improvement of their mobility. Five of them reported that the mobility improved a little bit, the other five patients reported that the mobility improved a lot.

Key words of the responses to the open questions about the motivations to join the dance class $(F)$. The questions were:

"What do you believe specifically makes this dance class work for you?"

"What brings you back to class each week?"

We give here a selection of the answers: 


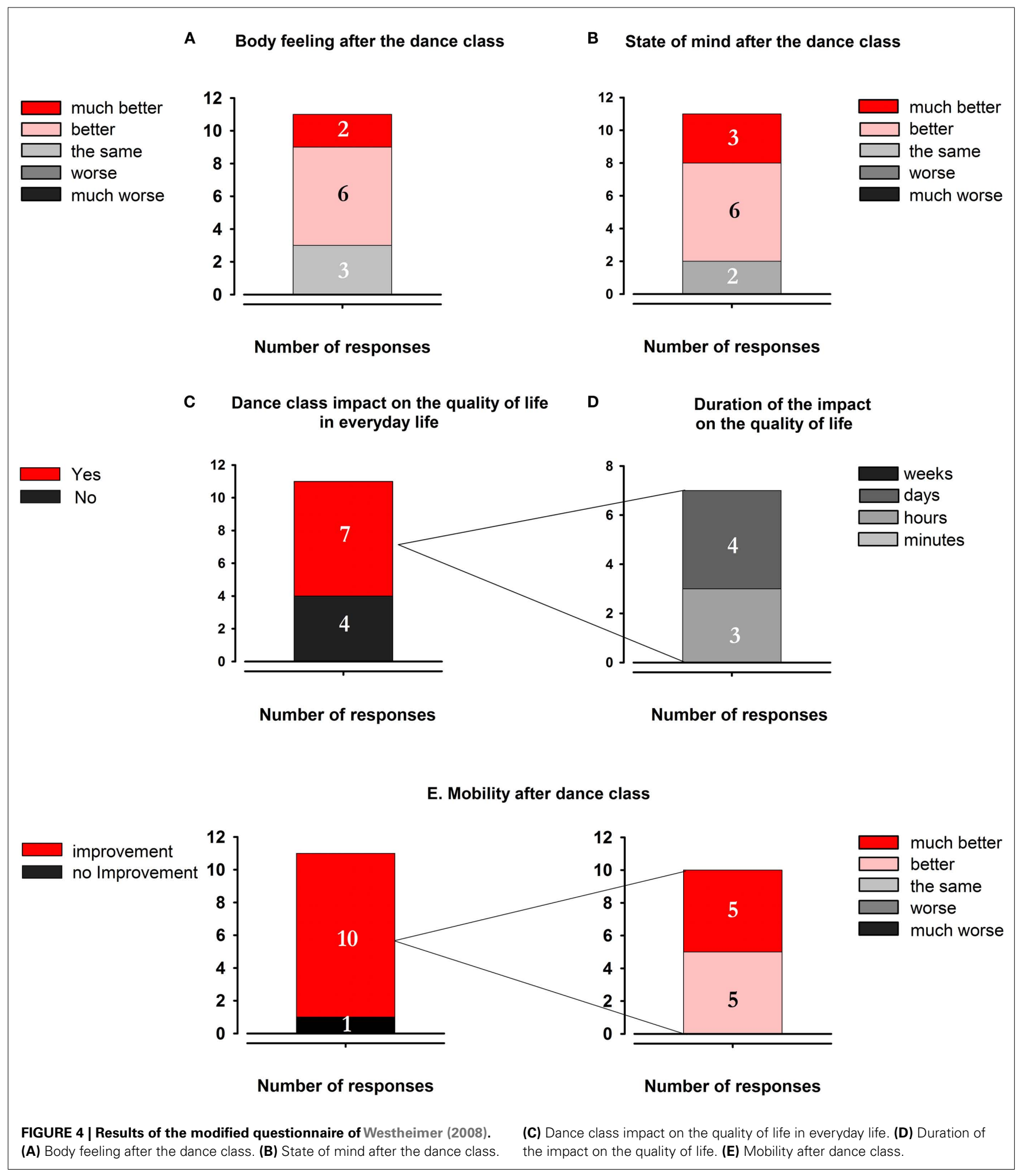

"Mood enhancement, satisfaction"; "The dance class is the highlight of the week"; "It feels good to be with many people. Otherwise I live in isolation."; "The movement, social contacts, music interpretation"; "Dancing is my great passion that I can enjoy during the dance class."; "I feel more flexible after dance class."; "Fun and joy, togetherness, the displacement of the disease. The jazz music gives me great pleasure."; "It is good for my body. The movement is crucial."; "It's fun. The people are nice. Dancing gives me a good feeling. It liberates me. Establishing contacts."; "The sense of community. The experience of the own body."; "The dance lesson is very important to me. It is a pleasure. Should take place more often. It makes me feel incredibly good and helps me to forget my 
illness."; "The rhythm. I want to fly. It gives me a swinging feeling. I feel relaxed after the dance lesson. Before I'm always very stiff."

\section{Questionnaire for caregivers}

\section{The answers to the closed questions were as followed:}

A1 Functional mobility of the patient: two from four caregivers recognized a slight improvement.

A2 State of mind of the patient: all four caregivers indicated that the state of mind of their partners improved.

A3 Impact of the dance class on the quality of life of everyday life: one caregiver perceived some little changes in everyday life.

$\mathrm{B}$ Changes in the relationship: three caregivers have recognized changes in the relationship with their partners since the participation at the dance class.

C1 Listen in music: one caregiver reported that since beginning of the dance class, he and his partner listen a little bit more to music together.

C2 Dancing together: nobody of the caregivers indicated that they are dancing more often outside the dance class with their partners since the beginning of the Parkinson dance class.

C3 Repeating exercises at home: one caregiver reported that they never repeat the exercises. Two caregivers answered "rarely," and one caregiver "occasionally."

D The well-being of the caregiver himself after dance class: all four caregivers feel better after the dance class.

E Changes since the participation of the dance class: three caregivers affirmed that something had changed since the participation of the dance class.

$\mathrm{F}$ Changes for the caregiver since the participation of the dance class: all four caregivers confirmed that since the beginning of the dance class they realized positive changes on themselves.

Key words of the responses to the open questions $(B, E, F)$. The questions were:

"Has something changed in your relationship since the participation at the dance class?"

"Has anything changed for you (the caregiver) since the participation of the dance class?"

"Do you have noticed changes on yourself since the participation at the dance class?"

The answers were:

"To experience the joy of past dance lessons again and the moving on rhythmic melodies."; "I'm more relaxed.”; “The deliberate togetherness."

"The dancing improves quality of life. It is a wonderful diversification in daily life and shows that you can move around better and better the longer you practice."; "The positive experience of the partner."; "Social contacts with other participants. Open discussions on the impact of the disease with other affected persons."; "After every dance lesson I am happy and lively. The lilting melodies accompany me the whole week."; "I have seen the dance as poetry."; "I am more relaxed after the dance class. Establishing contacts is easier."

\section{DISCUSSION}

Immediately after $1 \mathrm{~h}$ of dance class in a ballet studio, the disease severity, as evidenced in the total UPDRS motor score of Parkinson patients significantly improved. Most significant was the decrease in the rigidity scores, specifically for arms and legs on the right and left body sides, as well for finger taps, hand movements and facial expression. These improvements were found not only in the 11 patients subjected to the motor assessments after 8 months of regular participation in the PD dance class, but as well in the three de novo patients whose assessment was made in their second dance class. The measures of gait and balance by the TUG and SeTa tests did not show any short-term significant changes.

Our study also demonstrates that the regular participation in a PD dance class during 8 months leads to an improvement of the quality of life and of the well-being of the patients and their caregivers. The strongest amelioration was reported for social life, health, body-feeling and mobility, state of mind and everyday life. Quality of life and well-being of patients and caregivers are probably related to the better mobility. In the following paragraphs we discuss the various findings and outline possible underlying mechanisms.

\section{DANCE IMPACT ON THE MOBILITY, BALANCE, AND GATE OF PD PATIENTS \\ Improvements of rigidity and in hand and finger movements}

Most interesting is the finding that PD patients' major short-term improvement is a decrease in rigidity, one of the cardinal signs of $\mathrm{PD}$. What are the underlying mechanisms causing rigidity? One hypothesis considers that suppression of automatic postural activity, a function of the cerebro-basal ganglia loops, is impaired in PD patients (Marsden et al., 1983; Rothwell et al., 1983; Mink, 1996; Kurtzer et al., 2008). In a previous study we have suggested that $\mathrm{PD}$ rigidity results from insufficient voluntary control of reflexive proprioceptive joint stabilization (Anastasopoulos et al., 2009). It is well known that kinesthesia is impaired in PD patients (Klockgether and Dichgans, 1994; Klockgether et al., 1995; Zia et al., 2000; Adamovich et al., 2001; Maschke et al., 2003; Maurer et al., 2003). Dancing improves proprioception through sustained movement repetition together with verbal and visual (reflection in mirrors) feedback (Ramsay and Riddoch, 2001; Schweiger, 2009). The improved rigidity in $\mathrm{PD}$ patients immediately after the dance class may be a direct consequence of better proprioceptive-motor integration. In addition, Holstege (2004) in his anatomical description of the emotional motor system suggests that this system exerts inhibitory effects on increased reflexive muscle tone. Therefore, it may have played a role in the decreased rigidity found after the dance class.

The significant improvement of the hand movements and finger tapping is probably a consequence of the reduced rigidity but this is not likely because rigidity and hypokinesia may have different underlying pathomechanisms. This is suggested by the absence of significant correlation between both items in our study (data not mentioned in the results).

Movement initiation and execution were faster and their amplitude larger. This is leading to better fine motor skills crucial for everyday activity. The improvements in hand and finger movements can also be explained by (i) activation of the emotional motor system and (ii) by motor learning effects.

It is known that PD patients have motor fluctuations. Therefore a reasonable question is whether the hours of medication intake 
may have an impact on the results. This is not the case because most of the patients were already in the decreasing phase of the active drug level of L-DOPA and dopamine agonists. The results show significant improvements in mobility instead of increase of motor symptoms (Table 5).

\section{Improvement of the facial expression}

Our study also revealed significant improvement of the facial expression. In PD patients the deficit in motor control often affects the facial muscles, leading to symptoms known as hypomimia or facial masking. This refers to the face being less expressive than usual and to the loss of so-called automatic movements, such as blinking and smiling. This impairment can lead to extreme interpersonal problems in the exchange of social contacts. For example, hypomimia can either be confused with depression or, conversely, can cause overlooking depression in PD patients. This leads to a mutual inhibition of empathy.

Mirror neuron mechanism suggests that we are able to understand the facial and body expression of others by internal motor simulation and that this thus should play an important role in empathy (Rizzolatti et al., 2009). Perceiving an emotion activates several brain areas which project to visceral effectors, the activation of which subsequently tune our mood to the observed emotion (Jeannerod, 2006, pp. 145-148). Many of our dance exercises included elements of strong emotional expression and theatrical pantomime. The significant improvement of the facial expression of our PD patients demonstrates the effectiveness of these exercises which ameliorates mutual empathy and understanding between patient and caregiver.

An additional mechanisms can contribute to the more expressive facial expression: the activation of the projections from the emotional motor system to specific facial muscles (Morecraft et al., 2001).

\section{Balance and gait}

The lack of improvement in stance and gait in the PD patients after the dance class seems surprising as, on the basis of the literature, large effects were expected. In fact, people who have danced regularly over their lives are known to have better balance and less variable gait than non-dancers (Verghese, 2006; Zhang et al., 2008). In elderly healthy subjects, dancing caused long-term improvements in balance, walking, everyday competence and physical fitness (McKinley et al., 2008; Eyigor et al., 2009; Hui et al., 2009; Kattenstroth, 2009; Wallmann et al., 2009). What is the reason for the lack of short-term effects on balance and gait in our study? One obvious reason is that the beneficial effects of the dance class could have been masked by fatigue directly after the dance class, as was mentioned by several patients on inquiry. It is also possible, that the effects on balance and walking only develop on a long-term scale and can not be clearly observed on the short-term scale as in our study. One cannot exclude another explanation: We applied multiple measurements of rigidity and motor skills for each limb separately whereas our balance and gait scores were rather few and coarse. This may have caused a reduced sensitivity for possible changes. Future studies with more sensitive measurements of balance and gait (platforms) could be performed in the ballett studio.

\section{DANCE IMPACT ON THE QUALITY OF LIFE OF THE PD PATIENTS}

Westheimer (2008) reported enhanced quality of life after 17 months regular participation in a PD dance class. We have estimated the changes of the quality of life over a period of 8 months of regular participation in the weekly dance class and found that the improvement in our patients already occurred after this shorter period.

\section{Socializing effects}

The outcome of the questionnaires confirmed the socializing effects of the dance class. The items of the QOLS that changed to the better as a result of attending the Parkinson dance class were: "recreation" and "socializing" on the first and second places, followed by "relationships" and "helping and encouraging others." The modified questionnaire of Westheimer (2008) revealed the social impact of the dance class. The caregivers' questionnaire confirmed the socializing influence even on the private relationship between partners which had changed for a better since the participation in the dance class.

Social interactions can enhance the motivation to attend the dance class, even when patients do not feel that well (PaloBengtsson et al., 1998; Harris, 2008). Participants have the chance to meet individuals confronted with the same health problems, to feel accepted, and understood. They also have the possibility to reinforce their relationship to their caregivers (Westheimer, 2008).

Table 5 | Hours of medication intake of I-DOPA or dopamine agonists.

\begin{tabular}{|c|c|c|c|c|c|c|c|c|c|c|c|c|c|c|}
\hline Patients & P1 & P2 & P3 & P4 & P5 & P6 & P7 & P8 & P9 & P10 & P11 & $P * 1$ & $P * 2$ & $\mathbf{P} * 3$ \\
\hline Hours of medication intake of & 7 & 7 & 7 & 7.30 & 8 & 7 & 7 & 8 & 7 & 7 & 7 & 7 & 7 & 7 \\
\hline \multirow[t]{5}{*}{ I-DOPA or dopamine agonists (h) } & & & & & & 10.30 & & & & 10.30 & & & 10.30 & 10 \\
\hline & 13 & 13 & 13 & 12.30 & & 13 & 12.30 & 13 & 12 & 13 & 13 & 13 & 13 & 13 \\
\hline & & & & & & 15.30 & & & & 15.30 & & & 15.30 & \\
\hline & 19 & 19 & 19.30 & 19 & & 19 & 18 & 19 & 19 & 19 & 19 & 19 & 19 & 19 \\
\hline & 22 & & & & & & & & & 22 & & & & 22 \\
\hline $\begin{array}{l}\text { Last medication before the } \\
\text { dance class (h) }\end{array}$ & 12.30 & 13 & 13 & 12.30 & 8 & 15.30 & 12.30 & 13 & 12 & 15.30 & 13 & 13 & 15.30 & 13 \\
\hline Beginning of the dance class (h) & 16.15 & & & & & & & & & & & & & \\
\hline
\end{tabular}

PD, Parkinson disease; $P 1-P 11$, patient 1-11; $P * 1-3$, de novo patient 1-3. 
Impact on the state of mind. As dancing is enjoyable, it allows to express feelings and takes mind and spirit away from thoughts of disease (Hackney and Earhart, 2009a). Individuals feel their mood "lightened" (Hackney et al., 2007a,b) and their anxiety decreased (Lesté and Rust, 1984). Therefore, dance classes are beneficial to the mood of PD patients and their caregivers (Westheimer, 2008). The choice of the music also has an important influence on the state of mind (Pacchetti et al., 2000). The positive atmosphere during the dance class is an additional important factor. Positive emotions engage auditory-motor mirror mechanisms, as listening to vocal expression of highly arousing emotions can activate the central representations of vocal and facial muscles related to the emotion being communicated (Warren et al., 2006). During our dance class we cultivated laughing, having fun and joy, and set a fire of happiness and pleasure.

In the modified questionnaire of Westheimer (2008) 9 of 11 patients reported that they felt an improvement of their state of mind after each dance class. The four caregivers confirmed this for their partners and for themselves.

\section{Impact on everyday life}

Dance combines many different factors that contribute to improve the competence needed in everyday life. It has been shown that elderly healthy persons with dance experience reached higher scores in the everyday competence questionnaire (ECQ) than persons without (Kattenstroth et al., 2010). The assessed aspects of the ECQ included independence in activities of daily living and mobility, social relations, general health status and life contentment.

To our knowledge, no study before has examined the duration of the positive effects of dancing on everyday competence after the dance class. Here, we show for the first time how long the influence of a weekly dance class can last. Seven of the 11 patients reported positive impact on the everyday life after each dance class. For three of them the positive effect lasted a few hours and for the other four even a few days.

\section{Impact on health}

Cultural activities, including music, singing, and dance have been reported to have an important impact on health and life style (Kreutz, 2008) and dancing in elderly individuals improves cardiovascular parameters, muscle strength, of posture and balance and of cognitive abilities (Kattenstroth et al., 2010). A very important beneficial factor of dancing is the music. As music is associated with emotions, it can induce "vitalization" influencing the activity of the autonomic nervous system and having an influence on the immune system (Koelsch and Siebel, 2005 for a review). This includes associations evoked by the music, as well as emotional (e.g., happy) and physical reactions (e.g., tensioned or relaxed). Dance improves the mood which plays an important role for the well-being and the health of PD patients.

The expression of emotions have health benefits too (Goodill, 2005). The results of the QOLS showed that the patients "express themselves more creatively" since the participation to a dance class. Expressing oneself and one's emotions leads to self-confidence.

Therefore, it is not surprising that in our study "health" was one of the items of the QOLS with the highest frequency of changes to the better as a result of attending the dance class. Further, all four caregivers felt better after the dance class and reported that they realized positive changes on themselves.

\section{NEUROSCIENCE OF DANCE: WHY DANCE IS HELPFUL FOR PD PATIENTS}

The concept of the PD dance class follows the discovery and interpretation of the mirror neurons in primates which are active during the performance of an action and the observation of the same action executed by the experimenter (Gallese et al., 1996; Rizzolatti et al., 1996). Brain imaging studies have shown that action observation and imitation in human can activate regions homolog to those found in monkeys (for a review see Rizzolatti et al., 2009). Action observation and imitation play a key role in dancing and several studies have reported activation of the human mirror neuron system in dancing, in particular when the person had learned or executed the movements previously (Calvo-Merino et al., 2006; Grafton and Cross, 2008; Cross et al., 2009). During the dance class the patients observe and simultaneously imitate the movements performed by the dance teacher. The dance lesson incorporates movements that the PD patients are executing everyday and through repetition the motor plans are stored. In this way, the activation of the mirror neuron system during dancing leads to improvement of motor functions. Another important aspect of dance is its esthetics and Calvo-Merino et al. (2008) showed that the mirror neuron system was particularly activated when movements were perceived as esthetical.

Auditory cues, especially music have large influence on motor functions including speech, on brain activity, and on bodily functions (Koelsch and Siebel, 2005). In PD patients it is known that auditory cues have an important impact on the motor system, increasing gait initiation, walking speed, and cadence and also reducing the severity of "freezing" and it has been suggested that the auditory cues may bypass the dysfunctional loop from basal ganglia to the supplementary motor area (McIntosh et al., 1997; Nieuwboer et al., 1997, 2007; Howe et al., 2003; Dibble et al., 2004). On the same line in healthy subjects, Brown et al. (2006), investigating brain activation patterns during dancing movement with and without music, reported that the regular and predictable rhythm of beats strongly activates cerebellar regions. They proposed that these activations may be mediated by subcortical auditory-motor pathways.

Dance embodies many aspects, such as sensory stimulation, physical activity and cognitive challenges, rhythmic motor coordination, balance, auditory and sensory stimulation, musical experience, social interaction, memory, perception, and expression of emotions. Therefore, dance can be classified as one of the enriched environments known to induce an increase of neurotrophic factors which promote brain plasticity (Kattenstroth et al., 2010). This can offer an additional explanation for the motor improvements after the dance class. In addition, physical activity can also affect the regulation of neurotransmitters, as suggested by Jeong et al. (2005) who reported that dance movement therapy enhanced the concentration of serotonin, the so-called happiness hormone. In this way dancing can make the $\mathrm{PD}$ patients feel better and have a better body awareness. The 5-HT1A, 5-HT1B, and 5-HT2C receptors have also been proposed as potential therapeutic targets for PD (Nicholson and Brotchie, 2002). Thus, increased serotonin levels 
by dancing could act on these receptors and have beneficial effect on PD patients.

Future research should be directed toward the impact of the weekly dance class in a ballet studio on depression in individuals with PD. Another line of research can be directed toward longitudinal fMRI activation studies of the reward system in the PD patients attending weekly dance classes. One can expect that listening to the music accompanying certain dance exercises will be related to higher activation of the reward system in professional dancers.

To our knowledge, there is no study showing this short-term effect of a dance class in healthy individuals. Kattenstroth et al. (2010) documented the beneficial long-term dance experience on multiple-choice reaction times, motor performance (steadiness, aiming, pin plugging, tapping), tactile performance (touch threshold, two-point-discrimination threshold), and cognitive performance. It will be interesting to use these tests before and after the dance class to investigate the short-term effect of the dance class. Further, the quality of life has to be investigated in healthy individuals too.

\section{CONCLUSION}

The present study revealed the immediate effects of dance (called here "short-term" effect) on the functional mobility of individuals with PD. We show for the first time to our knowledge that weekly dance classes for PD patients in a ballet studio have immediate positive effects on motor deficits, especially on the rigidity of the limbs as well as on fine motor skills and facial expression.

\section{REFERENCES}

Adamovich, S. V., Berkinblit, M. B., Hening, W., Sage, J., and Poizner, H. (2001). The interaction of visual and proprioceptive inputs in pointing to actual and remembered targets in Parkinson's disease. J. Neurosci. 104, 1027-1041.

Anastasopoulos, D., Maurer, C., Nasios, G., and Mergner, T. (2009). Neck rigidity in Parkinson's disease patients is related to incomplete suppression of reflexive head stabilization. Exp. Neurol. 217, 336-346.

Berrol, C. F. (1997). Dance/movement therapy with older adults who have sustained neurological insult: a demonstration project. Am. J. Dance Ther. 19, 135-160.

Bloem, B. R., Hausdorff, J. M., Visser, J. E., and Giladi, N. (2004). Falls and freezing of gait in Parkinson's disease: a review of two interconnected, episodic phenomena. Mov. Disord. 19, 871-884.

Brown, S., Martinez, M. J., and Parsons, L. M. (2006). The neural basis of human dance. Cereb. Cortex 16, 1157-1167.

Calvo-Merino, B., Grezes, J., Glaser, D. E., Passingham, R. E., and Haggard,

Furthermore, the quality of life of the patients and their caregivers improved in parallel over 8 months of regular participation. Due to the design of the present study, which is open labeled, we cannot conclude whether physical or social aspects of the dance class are at the origin of the improvements. But it is clear that many effects of the dance class can also not be measured by the applied tests. When looking at the video of the dance class (http://www. uniklinik-freiburg.de/neurologie/live/forschung/xpeeg.html) one can immediately see the large amount of motor learning the patients have accomplished over time. Patients are able to perform movement sequences which they cannot make when going to the doctor. It is often believed that it is very difficult to get PD patients to move more and many physical therapies and rehabilitation programs have very limited success. The weekly dance class for PD patients and their caregivers led by a dance teacher is a powerful way to activate the patients. To sum up, dance is a very efficient activity to improve mobility and well-being of PD patients.

\section{ACKNOWLEDGMENTS}

This study is devoted to my dearest parents who danced daily to fight with the PD of my mother and the dementia of my farther (Rumyana Kristeva). The authors thank to the patients who have taken part in the dance class and to the dance teachers Susanne Fucker and Bernardo Fallas. Thanks to Olie Westheimer, David Leventhal, Jonathan Heginbotham, and Misty Owen for sharing their experience of dance classes for PD patients and their caregivers in New York.

women. Arch. Gerontol. Geriatr. 48 84-88.

Fahn, S., Marsden, C. D., Calne, D. B., and Goldstein, M. (1987). Recent Developments in Parkinson's Disease, Vol. 2. Florham Park, NJ: Macmillan Health Care Information, 153-164.

Fallik, D. (2007). Finding new life trough movement: how a modern dance company helps Parkinson's disease patients loosen tight joints and lift spirits. Neurology 3, 30-33.

Gallese, V., Fadiga, L., Fogassi, L., and Rizzolatti, G. (1996). Action recognition in the premotor cortex. Brain 119(Pt 2), 593-609.

Goodill, S. W. (2005). An Introduction to Medical Dance/Movement Therapy: Health Care in Motion. Gateshead: Athenaeum Press.

Goodwin, V. A., Richards, S. H., Taylor, R. S., Taylor, A. H., and Campbell, J. L. (2008). The effectiveness of exercise interventions for people with Parkinson's disease: a systematic review and meta-analysis. Mov. Disord. 23, 631-640.

Grafton, S. T., and Cross, E. S. (2008). "Dance and the brain," in Learning, Arts and the Brain: The Dana Consortium Report on Arts and Cognition, eds C. Asbury and B. Rich (New York: Dana Press), 61-68.
Hackney, M. E., and Earhart, G. M. (2009a). Effects of dance on movement control in Parkinson's disease: a comparison of Argentine tango and American ballroom. J. Rehabil. Med. 41, 475-481.

Hackney, M. E., and Earhart, G. M. (2009b). Short duration, intensive tango dancing for Parkinson disease: an uncontrolled pilot study. Complement Ther. Med. 17, 203-207.

Hackney, M. E., Kantorovich, S., Levin, R., and Earhart, G. M. (2007a). Effects of tango on functional mobility in Parkinson's disease: a preliminary study. J. Neurol. Phys. Ther. 31, 173-179.

Hackney, M. E., Kantorovich, S., and Earhart, G. M. (2007b). A study on the effects of Argentine tango as a form of partnered dance for those with Parkinson disease and the healthy elderly. Am. J. Dance Ther. 29, 109-127.

Harris, J. (2008). Why dance for PD? Hints from neuroscience. Summary of a talk given at a workshop held at the English National Ballet on November 7th.

Holstege, G. (2004). The emotional motor system and micturition control. Neurourol. Urodyn. 29, 42-48. 
Howe, T. E., Lovgreen, B., Cody, F. W., Ashton, V. J., and Oldham, J. A. (2003). Auditory cues can modify the gait of persons with earlystage Parkinson's disease: a method for enhancing parkinsonian walking performance? Clin. Rehabil. 17, 363-367.

Hui, E., Chui, B. T., and Woo, J. (2009). Effects of dance on physical and psychological well-being in older persons. Arch. Gerontol. Geriatr. 49, e45-e50.

Jacobson, A. (2005). Argentine Tango Dancing as an Effective Means for Improving Cognition and Complex Task Performance in at-risk Elderly: A Feasibility Study. Society for Neuroscience Abstract Viewer/757.7.

Jeannerod, M. (2006). Motor Cognition: What Actions Tell the Self. Oxford: Oxford University Press.

Jeong, Y. J., Hong, S. C., Lee, M. S., Park, M. C., Kim, Y. K., and Suh, C. M. (2005). Dance movement therapy improves emotional responses and modulates neurohormones in adolescents with mild depression. Int. J. Neurosci. 115, 1711-1720.

Kattenstroth, J. C. (2009). "Beneficial effects of a sixth-months dance class on sensorimotor and cognitive performance of elderly individuals," in Proceedings of the Society for Neuroscience Meeting 2009 Chicago Poster 180.8 .

Kattenstroth, J. C., Kolankowska, I., Kalisch, T., and Dinse, H. R. (2010). Superior sensory, motor, and cognitive performance in elderly individuals with multi-year dancing activities. Front. Aging Neurosci. 2:31. doi:10.3389/fnagi.2010.00031

Klockgether, T., Borutta, M., Rapp, H., Spieker, S., and Dichgans, J. (1995). A defect of kinesthesia in Parkinson's disease. Mov. Disord. 10, 460-465.

Klockgether, T., and Dichgans, J. (1994). Visual control of arm movement in Parkinson's disease. Mov. Disord. 9, 48-56.

Koelsch, S., and Siebel, W. A. (2005). Towards a neural basis of music perception. Trends Cogn. Sci. (Regul. Ed.) 9, 578-584.

Kreutz, G. (2008). Does partnered dance promote health? The case of tango Argentino. J. R. Soc. Promot. Health 128, 79-84.

Kurtzer, I. L., Pruszynski, J. A., and Scott, S. H. (2008). Long-latency reflexes of the human arm reflect an internal model of limb dynamics. Curr. Biol. 18, 449-453.

Lesté, A., and Rust, J. (1984). Effects of dance on anxiety. Percept. Mot. Skills 58, 767-772.

Marsden, C. D., Rothwell, J. C., and Day, B. L. (1983). Long-latency automatic responses to muscle stretch in man: origin and function. Adv. Neurol.39, 509-539.

Maschke, M., Gomez, C. M., Tuite, P. J., and Konczak, J. (2003). Dysfunction of the basal ganglia, but not the cerebellum, impairs kinaesthesia. Brain 126, 2312-2322.

Maurer, C., Mergner, T., Xie, J., Faist, M., Pollak, P., and Lucking, C. H. (2003). Effect of chronic bilateral subthalamic nucleus (STN) stimulation on postural control in Parkinson's disease. Brain 126, 1146-1163.

McIntosh, G. C., Brown, S. H., Rice, R. R., and Thaut, M. H. (1997). Rhythmic auditory-motor facilitation of gait patterns in patients with Parkinson's disease. J. Neurol. Neurosurg. Psychiatr. 62, 22-26.

McKinley, P., Jacobson, A., Leroux, A., Bednarczyk, V., Rossignol, M., and Fung, J. (2008), Effect of a community-based Argentine tango dance program on functional balance and confidence in older adults. J. Aging Phys. Act. 16, 435-453.

Mink, J. W. (1996). The basal ganglia: focused selection and inhibition of competing motor programs. Prog. Neurobiol. 50, 381-425.

Morecraft, R. J., Louie, J. L., Herrick, J. L., and Stilwell-Morecraft, K. S. (2001). Cortical innervation of the facial nucleus in the non-human primate: a new interpretation of the effects of stroke and related subtotal brain trauma on the muscles of facial expression. Brain 124, 176-208.

Ng, S. S., and Hui-Chan, C. W. (2005). The timed up and go test: its reliability and association with lowerlimb impairments and locomotor capacities in people with chronic stroke. Arch. Phys. Med. Rehabil. 86, 1641-1647.

Nicholson, S. L., and Brotchie, J. M. (2002). 5-hydroxytryptamine (5-HT, serotonin) and Parkinson's disease-opportunities for novel therapeutics to reduce the problems of levodopa therapy. Eur. J. Neurol. 9, 1-6.

Nieuwboer, A., Feys, P., de Weerdt, W., and Dom, R. (1997). Is using a cue the clue to the treatment of freezing in Parkinson's disease? Physiother. Res. Int. 2, 125-132; discussion 133-124.

Nieuwboer, A., Kwakkel, G., Rochester, L., Jones, D., van Wegen, E., Willems, A. M., Chavret, F., Hetherington, V., Baker, K., and Lim, I. (2007). Cueing training in the home improves gait-related mobility in Parkinson's disease: the RESCUE trial. J. Neurol. Neurosurg. Psychiatr. 78, 134-140.

Pacchetti, C., Mancini, F., Aglieri, R., Fundaro, C., Martignoni, E., and Nappi, G. (2000). Active music therapy in Parkinson's disease: an integrative method for motor and emotional rehabilitation. Psychosom. Med. 62, 386-393.

Palo-Bengtsson, L., Winblad, B., and Ekman, S. L. (1998). Social dancing: a way to support intellectual, emotional and motor functions in persons with dementia. J. Psychiatr. Ment. Health Nurs. 5, 545-554.

Podsiadlo, D., and Richardson, S. (1991). The timed "up and go": a test of basic functional mobility for frail elderly persons. J. Am. Geriatr. Soc. 39, 142-148.

Ramsay, J. R., and Riddoch, M. J. (2001). Position-matching in the upper limb: professional ballet dancers perform with outstanding accuracy. Clin. Rehabil. 15, 324-330.

Rizzolatti, G., Fabbri-Destro, M., and Cattaneo, L. (2009). Mirror neurons and their clinical relevance. Nat. Clin. Pract. Neurol. 5, 24-34.

Rizzolatti, G., Fadiga, L., Gallese, V., and Fogassi, L. (1996). Premotor cortex and the recognition of motor actions. Brain Res. Cogn. Brain Res. 3, 131-141.

Rothwell, J. C., Obeso, J. A., Traub, M. M., and Marsden, C. D. (1983). The behaviour of long- latency stretch reflex in patients with Parkinson's disease. J. Neurol. Neurosurg. Psychiatr. 46, 35-44.

Schweiger, E. G. (2009). "Dance-specific training effects on upper limb proprioceptive acuity," in Proceedings of the Society for Neuroscience Meeting Chicago Poster 272.23.

Verghese, J. (2006). Cognitive and mobility profile of older social dancers. J. Am. Geriatr. Soc. 54 1241-1244.
Wallmann, H. W., Gillis, C. B., Alpert, P. T., and Miller, S. K. (2009). The effect of a senior jazz dance class on static balance in healthy women over 50 years of age: a pilot study. Biol. Res. Nurs. 10, 257-266.

Warren, J. E., Sauter, D. A., Eisner, F. Wiland, J., Dresner, M. A., Wise, R. J., Rosen, S., and Scott, S. K. (2006). Positive emotions preferentially engage an auditory-motor “mirror" system. J. Neurosci. 26, 13067-13075.

Westbrook, M., and McKibben, $\mathrm{H}$. (1989). Dance/movement therapy with groups of outpatients with Parkinson's disease. Am. J. Dance Ther. 11, 27-38.

Westheimer, O. (2008). Why dance for Parkinson's disease. Top. Geriatr. Rehabil. 24, 127-140.

Zhang, X., Riemer, R., and HsiaoWecksler, E. T. (2008). Uncertainties in inverse dynamics solutions: a comprehensive analysis and an application to gait. Gait Posture 27, 578-588.

Zia, S., Cody, F., and O'Boyle, D. (2000). Joint position sense is impaired by Parkinson's disease. Ann. Neurol. 47, 218-228.

Conflict of Interest Statement: The authors declare that the research was conducted in the absence of any commercial or financial relationships that could be construed as a potential conflict of interest.

Received: 30 June 2011; paper pending published: 20 July 2011; accepted: 18 September 2011; published online: 10 October 2011.

Citation: Heiberger L, Maurer C, Amtage F, Mendez-Balbuena I, Schulte-Mönting $J$, Hepp-Reymond $M-C$ and Kristeva $R$ (2011) Impact of a weekly dance class on the functional mobility and on the quality of life of individuals with Parkinson's disease. Front. Ag. Neurosci 3:14. doi: 10.3389/fnagi.2011.00014 Copyright (c) 2011 Heiberger, Maurer, Amtage, Mendez-Balbuena, SchulteMönting, Hepp-Reymond and Kristeva. This is an open-access article subject to a non-exclusive license between the authors and Frontiers Media SA, which permits use, distribution and reproduction in other forums, provided the original authors and source are credited and other Frontiers conditions are complied with. 


\section{APPENDIX \\ QUALITY OF LIFE SCALE \\ Sixteen-item Oregon Health and Science University version + 17th item of the Brooklyn Parkinson Group (BPG)}

Please read each item and circle the number that best describes how satisfied you are at this time. Please answer each item even when you do not currently participate in an activity or have a relationship. You can be satisfied or dissatisfied with doing the activity or having the relationship.

(Note: Participants were asked to rate their feelings on a scale of 1-7: Terrible, Unhappy, Mostly Dissatisfied Mixed Mostly Satisfied Pleased or Delighted).

1. Material comforts - home, food, conveniences, financial security.

2. Health - being physically fit and vigorous.

3. Relationships with parents siblings and other relatives - communcating, visiting, helping.

4. Having and rearing children.

5. Close relationships with spouse or significant other.

6. Close friends.

7. Helping and encouraging others, volunteering, giving advice.

8. Participating in organizations and public affairs.

9. Learning - attending school, improving understanding, getting additional knowledge.

10. Understanding yourself - knowing your assets and limitations - knowing what life is about.

11. Work - job or in home.

12. Expressing yourself creatively

13. Socializing - meeting other people, doing things, parties, etc.

14. Reading, listening to music, or observing entertainment.

15. Participating in active recreation.

16. Independence, doing for yourself.

17. Moving around - walking, standing-up (17 was added by BPG).

After completing the QOL 5, respondents were asked by BPG: "Have any of the numbered items, 1-17, changed for me better as a result of attending the Dance for PD classes? If so, please write the numbers below."

\section{MODIFIED QUESTIONNAIRE OF ?}

A. How is your body-feeling after the dance class?

1. much better

2. better

3. the same

4. worse

5. much worse

B. How is your state of mind after the dance class?

1. much better

2. better

3. the same

4. worse

5. much worse

C. Do you feel the consequences of the dance class impact your quality of life on a daily basis? Yes No

D. If yes, how long do you feel that the impact last?
1. minutes

2. hours

3. days

4. weeks

E. How is your mobility after dance class?

1. much better

2. better

3. the same

4. worse

5. much worse

F. Open questions (please describe in detail):

- What do you believe specifically makes dais dance class work for you?

- What brings you back to class each week?

\section{QUESTIONNAIRE FOR CAREGIVERS}

A. Which changes do you have observed on your partner since his participation at the dance class...

1.... concerning his functional mobility

1. strong deterioration

2. slight deterioration

3. no changes

4. slight improvement

5. strong improvement

2.... concerning his slate of mind

1. strong deterioration

2. slight deterioration

3. no changes

4. slight improvement

5. strong improvement

3.... in everyday life, concerning the everyday life activity

1. strong deterioration

2. slight deterioration

3. no changes

4. slight improvement

5. strong improvement

B. Has something changed in your relationship since the participation at the dance class?

Yes No

If yes, what has changed? (please describe in detail)

C. What do you (as a couple) take home from the dance class?

1. Do you listen more to music together?

1. much less than before participating at dance class

2. less than before participating at dance class

3. no difference from before participating at dance class

4. a little more since the participation at dance class

5. significantly more since the participation at dance class

2. Do you go out for dancing together?

1. much less than before participating at dance class

2. less than before participating at dance class

3. no difference from before participating at dance class

4. a little more since the participation at dance class

5. significantly more since the participation at dance class

3. Do you repeat the dance exercise at home together?
1. never
2. rarely
3. occasionally 
4. often

5. always

D. How do you (the caregiver) feel after the dance class?

1. much batter

2. better

3. the same

4. worse

5. much worse
Open questions:

E. Has anything changed for you (the caregiver) since the participation of the dance class? Yes No

If yes, what has changed? (please describe in detail)

F. Do you have noticed changes on yourself since the participation at the dance class? Yes No

If yes, which changes do you have noticed? (please describe in detail) 